\title{
Mother Awareness Regarding Oral Contraceptive Pills in Family Planning Center in Kirkuk City
}

\author{
Elham Saeed Shaker* \\ Salwa Hazim Al Mukhtar **
}

\begin{abstract}
Background and aim: The family planning involves choosing if and when to have children. It includes contraception, the prevention of pregnancy as well as methods to achieve pregnancy this method used by couples having difficulty attaining pregnancy. In addition, using contraceptives has been shown to promote a woman's sense of autonomy and increase her ability to make decisions in other areas of her life This study aims at identifying mother's awareness regarding to oral contraceptive pills in Kirkuk city, as well as to find a relationship between women's knowledge and attitude with some socio- demographic characteristics such as (mother's age, level of education, occupation, number of children, socioeconomic status, medical data, miscarriage and parity).

Materials and method: A descriptive study Probability (Purposive sample) consists of 500 women who attended the typical primary health care centers in Kirkuk city, for a period from November, $1^{\text {st }}, 2013$ to October, $1^{\text {st }}, 2014$. Constructed questionnaire designed to questioned women's about oral contraceptive pills, The data were collected through the use of the interview. They were analyzed through the application of descriptive statistical analysis (frequency and percentage) and inferential statistical data analysis (ANOVA).

Results: The findings of the study indicated that (37\%) were in the age group (35 and above), and (37.7\%) of the sample were graduating from primary school, (78.2\%) of them were a housewife, $(59.2 \%)$ of the sample had barely sufficient monthly income. The study indicated that $(41 \%)$ have $(1-3)$ children, and (59.6\%) had no history of chronic disease.

Conclusion: Further studies include samples from rural areas and compare their awareness to the urban women regarding family planning methods.

Recommendations: the study found a high awareness regarding to oral contraceptive pills among women. In addition, a significant relationship was found between level of education, number of children and awareness regarding to oral contraceptive pills.
\end{abstract}

Keywords: Awareness, Contraceptive pills Ectopic pregnancy, Family Planning, Mini pill, miscarriage.

\section{INTRODUCTION}

The family planning is one of several avenues for reducing population growth and demographic pressure. Reduced population sizes mean decreased burden on national expenditures for education, health, and other social services, as less strain on the environment and natural resources. Family planning also directly contributes to improved health in terms of reduced infant and maternal mortality and morbidity. Repositioning family planning as a key component of multispectral povertyreduction programs not only increases support for family planning, but makes it logistically more feasible and more affordable for countries to achieve poverty reduction and related goals (Usha et. al., 2004; Stefano, 2013). The health impact of family planning occurs through the avoidance of unwanted pregnancies, limiting the number of births, particularly the first and last in relation to the age of the mother (Jaypee, 2008).
Family planning allows individuals and couples to determine and ascertain the desired number of children as well as the spacing of their pregnancies. Contraceptive methods and the treatment of involuntary infertility are used to achieve the purpose. Spacing and limiting pregnancies have a direct impact on women's health and well-being as well as to the outcome of each pregnancy. Short birth spacing has significant health effects on both mothers and children. Low birth weight, premature birth and small for gestational age are among its consequences to babies. To women, they are more likely to suffer from third trimester bleeding, premature rupture of membrane and anemia (Conde et. al., 2000; Shafei et. al., 2012)

The mass media also play an important role in the promotion and acceptability of contraception (A.I. Mahadeen; and Hamdan, 2012) Oral contraceptives or birth control pills ("the pill") are used by women to prevent

\footnotetext{
* Assistant Lecturer/Kirkuk Technical Institute.

** Assistant Professor/College of Nursing/University of Mosul
} 
pregnancy, to regulate the cycle and to provide hormone replacement therapy. Birth control pills have two basic types first. Combination pills, which contain the hormones estrogen and progestin, and second types progestin only pills, Combined birth control pills work mainly by stopping ovulation if there is no egg to meet with sperm, pregnancy cannot occur. Reversible effects on the cervical mucus and uterine lining also discourage pregnancy. Under ideal conditions, oral contraceptive have an effective rate of over 99.5\% (Berkeley, 2009; Motant, 2008).

The most commonly used forms of oral contraceptives (OC) are a combination of ethinyl estradiol and a progestin. They work by blocking ovulation and changing the cervical mucus and the lining of the uterus (Susan, 2006) .There is no conclusive evidence that the pill causes cancer. Recent data have shown a lower incidence of uterine and ovarian cancer in women who have taken the pill. More research needs to be done regarding the pill's relationship to breast and cervical cancer. Possible befits of taking the pill include a decreased incidence of ovarian cysts, benign changes, iron deficiency anemia, pelvic infections, ectopic pregnancy, acne, menstrual cramps and long, heavy menstrual flow (Berkeley, 2009). Some women experience a variety of minor discomforts when starting the pill. Some of these symptoms may be nausea, breakthrough bleeding, breast enlargement or tenderness, slight weight gain, mood changes, and changes in Libido. Most of these symptoms will disappear within the first three cycles of the pill. Acne, though often improved in the long run, may worsen for a couple of months when you first start the pill (Berkeley, 2009; Motant, 2008). In my country the most popular method is the pill which is used by 15 percent of married women in Iraq, the next most popular method is the IUD, which accounts for 12 percent of married women, eight and seven percent of women reported use of the withdrawal method and the lactational amenorrhea method (LAM) respectively. Between two and three percent of women reported use of female sterilization,periodic abstinence and injectables, condom use is very rare; only one percent of married women reported using it as a method of contraception (Kurdistan regional statistics office, 2006).

\section{MATERIALS AND METHOD}

A descriptive study was carried out from $1^{\text {st }}$ November 2013 to $1^{\text {st }}$ October 2014 in order to achieve the objectives of the present study. The present study was conducted in four typical Primary Health Care center (PHC) at Kirkuk City, which is located in the northern region of Iraq. Probability (purposive)sample consists of (500) women who were attending the typical primary health care center to receive contraceptive pills at Kirkuk city. Kirkuk health directorate classified Kirkuk city into two sectors, first sector includes (17) PHCCs and the second sector includes (13) PHCCs. The researcher chose only four of the typical PHCCs which includes the family planning center. For the purpose of the current study, a questionnaire format was constructed to identify the mothers' awareness regarding to oral contraceptive pills at the family planning centers in Kirkuk city . The questionnaire format was based on the review of literatures and related previous studies. The study instrument was comprised of five parts. Part one: demographic data sheet was developed by the researcher in order to collect additional information about the participants in this study. The process of data collection was conducted during a period of four months, extending from January, $1^{\text {st }}, 2014$ to April, 10 ${ }^{\text {th }}, 2014$. Data was analyzed by Statistical Package SPSS (version 19.0).

\section{RESULTS}

Table (1): Demonstrates Socio-demographic characteristics of the Whole Study Sample

\begin{tabular}{||l|c|c|c|}
\hline Variables & Frequency $(\boldsymbol{f})$ & Percentage (\%) \\
\hline \multirow{4}{*}{ Age } & $15-19$ year & 3 & 0.6 \\
\cline { 2 - 4 } & $20-24$ year & 38 & 7.6 \\
& $25-29$ year & 94 & 5 \\
\cline { 2 - 4 } & 30-34 year & 180 & 36 \\
\cline { 2 - 5 } & 35 years and above & 185 & 37 \\
\hline Total & $\mathbf{5 0 0}$ & $\mathbf{1 0 0}$ \\
\hline Mean \pm SD = 30-34 $\pm \mathbf{0 . 9 5 8}$ & Employee & 78 & 15.6 \\
\hline Occupation of women & \multicolumn{2}{|c|}{} \\
\hline
\end{tabular}




\begin{tabular}{|c|c|c|c|}
\hline & Housewife & 391 & $\overline{78.2}$ \\
\hline & Student & 31 & 6.2 \\
\hline \multicolumn{2}{|l|}{ Total } & 500 & 100 \\
\hline \multirow{4}{*}{ Occupation of husband } & Employee & 183 & 36.6 \\
\hline & Free work & 287 & 57.4 \\
\hline & Jobless & 16 & 3.2 \\
\hline & Retired & 14 & 2.8 \\
\hline \multicolumn{2}{|l|}{ Total } & 500 & 100 \\
\hline \multirow{7}{*}{ Level of Education for the women } & Not Read and not write & 29 & 5.8 \\
\hline & Read and write & 32 & 6.4 \\
\hline & Primary School & 188 & 37.7 \\
\hline & Intermediate School & 97 & 19.4 \\
\hline & Secondary School & 77 & 15.4 \\
\hline & Institutes & 58 & 11.6 \\
\hline & College and above & 19 & 3.8 \\
\hline \multicolumn{2}{|l|}{ Total } & 500 & 100 \\
\hline \multirow{7}{*}{ Level of education for the husband } & Not Read and not write & 18 & 3.6 \\
\hline & Read and write & 30 & 6 \\
\hline & Primary School & 107 & 21.4 \\
\hline & Intermediate School & 93 & 18.6 \\
\hline & Secondary School & 99 & 19.8 \\
\hline & Institute & 104 & 20.8 \\
\hline & College and above & 49 & 9.8 \\
\hline \multicolumn{2}{|l|}{ Total } & 500 & 100 \\
\hline \multirow{3}{*}{ Number of Children } & $\begin{array}{l}1-3 \\
43\end{array}$ & 205 & 41 \\
\hline & $4-6$ & 202 & 40.4 \\
\hline & 7 and above & 93 & 18.6 \\
\hline \multicolumn{2}{|l|}{ Total } & 500 & 100 \\
\hline \multirow{3}{*}{ Socio-Economic Status } & Sufficient & 69 & 13.8 \\
\hline & Barely Sufficient & 296 & 59.2 \\
\hline & Insufficient & 135 & 27 \\
\hline \multicolumn{2}{|l|}{ Total } & 500 & 100 \\
\hline \multirow{2}{*}{ Type of the Family } & Nuclear & 403 & 80.6 \\
\hline & Extended & 97 & 19.4 \\
\hline \multicolumn{2}{|l|}{$\begin{array}{l}\text { Total } \\
120\end{array}$} & 500 & 100 \\
\hline
\end{tabular}

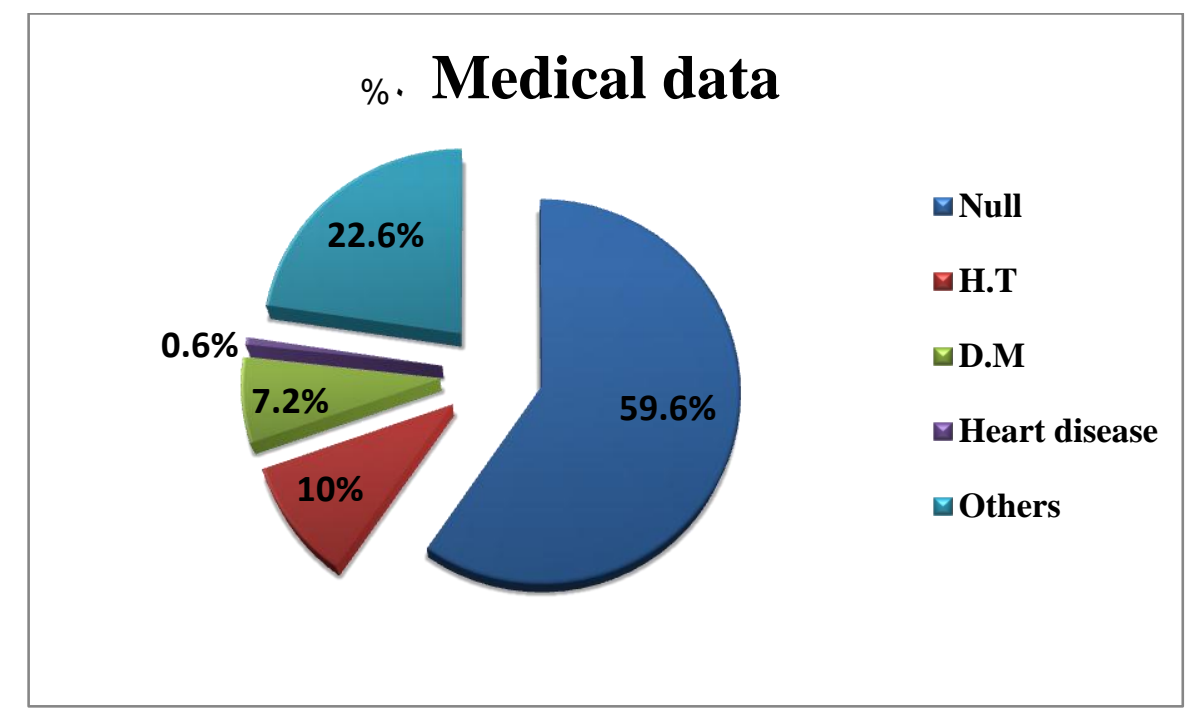

Figure (1): Distribution percentage of medical data in the whole study. 
Table (2): Distribution of the study Sample according to reproductive history ( $N=500)$

\begin{tabular}{|c|c|c|}
\hline Variables & Frequency $(f)$ & Percentage (\%) \\
\hline \multicolumn{3}{|l|}{ Years of marriage } \\
\hline Less than 5 years & 29 & 5.8 \\
\hline $5-9$ years & 96 & 19.2 \\
\hline $10-14$ years & 151 & 30.2 \\
\hline 15 years and above & 224 & 44.8 \\
\hline Total & 500 & 100 \\
\hline \multicolumn{3}{|c|}{ Mean \pm SD $=10-14 \pm 0.924$} \\
\hline \multicolumn{3}{|l|}{ Age of menarche } \\
\hline $10-11$ years & 76 & 15.2 \\
\hline $12-13$ years & 312 & 62.4 \\
\hline $14-15$ years & 104 & 20.8 \\
\hline 16 years and above & 8 & 1.6 \\
\hline Total & 500 & 100 \\
\hline \multicolumn{3}{|c|}{ Period of menstrual cycle } \\
\hline Less than 3 days & 116 & 23.2 \\
\hline $4-6$ days & 304 & 60.8 \\
\hline $7-9$ days & 78 & 15.6 \\
\hline 10 days and above & 2 & 0.4 \\
\hline Total & 500 & 100 \\
\hline \multicolumn{3}{|l|}{ Menstrual cycle } \\
\hline Regular & 338 & 67.6 \\
\hline Irregular & 162 & 32.4 \\
\hline Total & 500 & 100 \\
\hline \multicolumn{3}{|c|}{ Pain during menstruation } \\
\hline Mild & 43 & 8.6 \\
\hline Moderate & 280 & 56 \\
\hline Severe & 177 & 35.4 \\
\hline Total & 500 & 100 \\
\hline \multicolumn{3}{|c|}{ Quantity of menstruation } \\
\hline Little & 122 & 24.4 \\
\hline Normal & 331 & 66.2 \\
\hline Heavy & 47 & 9.4 \\
\hline Total & 500 & 100 \\
\hline Variables & Frequency $(f)$ & Percentage (\%) \\
\hline \multicolumn{3}{|l|}{ Number of gravida } \\
\hline $1-3$ & 166 & 33.2 \\
\hline $4-6$ & 265 & 53 \\
\hline 7 and above & 69 & 13.8 \\
\hline Total & 500 & 100 \\
\hline \multicolumn{3}{|l|}{ Number of parity } \\
\hline $1-3$ & 197 & 39.4 \\
\hline $4-6$ & 257 & 51.4 \\
\hline 7 and above & 46 & 9.2 \\
\hline Total & 500 & 100 \\
\hline \multicolumn{3}{|c|}{ Number of miscarriage/abortion } \\
\hline Null & 315 & 63 \\
\hline $1-3$ & 121 & 24.2 \\
\hline $4-6$ & 53 & 10.6 \\
\hline 7 and above & 11 & 2.2 \\
\hline Total & 500 & 100 \\
\hline
\end{tabular}




\begin{tabular}{|c|c|c|}
\hline 1-3 years & 196 & 39.2 \\
\hline $4-6$ years & 171 & 34.2 \\
\hline 7 years and above & 133 & 26.6 \\
\hline Total & 500 & 100 \\
\hline \multicolumn{3}{|c|}{ From where did you get contraceptive pills } \\
\hline Family planning centers & 254 & 50.8 \\
\hline Direct pharmacy & 1 & 0.2 \\
\hline Primary center and pharmacy & 245 & 49 \\
\hline Total & 500 & 100 \\
\hline \multicolumn{3}{|c|}{ Type of family planning used previously } \\
\hline Pills & 221 & 44.2 \\
\hline Injection & 37 & 7.4 \\
\hline Condom & 1 & 0.2 \\
\hline IUCD & 99 & 19.8 \\
\hline Condom and pills & 142 & 28.4 \\
\hline Total & 500 & 100 \\
\hline
\end{tabular}

Table (3): Grand Mean of Score and Assessment of Mother Awareness and Attitudes Regarding to Oral Contraceptive Pills

\begin{tabular}{||l|l|c|c|}
\hline NO. & Mothers' Knowledge and attitude category & GMS & Assessment \\
\hline 3. & General information about oral contraceptive pills & 2.78 & Adequate \\
\hline 4. & Complications of oral contraceptive pills & 2.84 & Adequate \\
\hline $\mathbf{5 .}$ & Benefits of oral contraceptive pills & 2.84 & Adequate \\
\hline 6. & Mothers attitude regarding to oral contraceptive pills & 2.86 & Adequate \\
\hline \multicolumn{2}{|l|}{ Total } & $\mathbf{2 . 8 3 ~ 2 . 8}$ & \\
\hline
\end{tabular}

Table (4): Association of the women knowledge and attitudes regarding to oral contraceptive pills and their level of education

\begin{tabular}{|c|c|c|c|c|c|c|}
\hline \multicolumn{2}{|c|}{ Categories } & \multirow{2}{*}{$\begin{array}{c}\begin{array}{c}\text { Sum of } \\
\text { Squares }\end{array} \\
3725.695\end{array}$} & \multirow{2}{*}{$\frac{\text { df }}{6}$} & \multirow{2}{*}{$\begin{array}{c}\begin{array}{c}\text { Mean } \\
\text { Square }\end{array} \\
620.949 \\
\end{array}$} & F. & Sig. \\
\hline \multirow{3}{*}{ General Information } & Between Groups & & & & \multirow{3}{*}{125.080} & \multirow{3}{*}{$\begin{array}{c}0.000 \\
\text { H.S }\end{array}$} \\
\hline & Within Groups & 2447.447 & 493 & 4.964 & & \\
\hline & Total & 6173.142 & 499 & & & \\
\hline \multirow{3}{*}{ Complication } & Between Groups & 598.188 & 6 & 99.698 & \multirow{3}{*}{92.945} & \multirow{3}{*}{$\begin{array}{c}0.000 \\
\text { H.S }\end{array}$} \\
\hline & Within Groups & 528.820 & 493 & 1.073 & & \\
\hline & Total & 1127.008 & 499 & & & \\
\hline \multirow{3}{*}{ Benefits } & Between Groups & 1045.895 & 6 & 174.316 & \multirow{3}{*}{117.738} & \multirow{3}{*}{$\begin{array}{c}0.000 \\
\text { H.S }\end{array}$} \\
\hline & Within Groups & 729.905 & 493 & 1.481 & & \\
\hline & Total & 1775.800 & 499 & & & \\
\hline \multirow{3}{*}{ Attitude } & Between Groups & 1849.187 & 6 & 308.198 & \multirow{3}{*}{134.938} & \multirow{3}{*}{$\begin{array}{c}0.000 \\
\text { H.S }\end{array}$} \\
\hline & Within Groups & 1126.013 & 493 & 2.284 & & \\
\hline & Total & 2975.200 & 499 & & & \\
\hline
\end{tabular}


Table (5): Association of the women knowledge and attitudes regarding to oral contraceptive pills and their occupation

\begin{tabular}{|c|c|c|c|c|c|c|}
\hline \multicolumn{2}{|l|}{ Categories } & \multirow{2}{*}{$\begin{array}{c}\begin{array}{c}\text { Sum of } \\
\text { Squares }\end{array} \\
318.626 \\
\end{array}$} & \multirow{2}{*}{$\frac{\text { df }}{2}$} & \multirow{2}{*}{\begin{tabular}{|c|} 
Mean Square \\
159.313 \\
\end{tabular}} & F. & Sig. \\
\hline \multirow{3}{*}{\begin{tabular}{|l} 
General \\
Information
\end{tabular}} & Between Groups & & & & \multirow{3}{*}{13.524} & \multirow{3}{*}{$\begin{array}{l}0.000 \\
S\end{array}$} \\
\hline & Within Groups & 5854.516 & 497 & 11.780 & & \\
\hline & Total & 6173.142 & 499 & & & \\
\hline \multirow{3}{*}{ Complication } & Between Groups & 52.142 & 2 & 26.071 & \multirow{3}{*}{12.055} & \multirow{3}{*}{$\begin{array}{l}0.000 \\
S\end{array}$} \\
\hline & Within Groups & 1074.866 & 497 & 2.163 & & \\
\hline & Total & 1127.008 & 499 & & & \\
\hline \multirow{3}{*}{ Benefits } & Between Groups & 76.937 & 2 & 38.469 & \multirow{3}{*}{11.254} & \multirow{3}{*}{$\begin{array}{c}0.000 \\
S\end{array}$} \\
\hline & Within Groups & 1698.863 & 497 & 3.418 & & \\
\hline & Total & 1775.800 & 499 & & & \\
\hline \multirow{3}{*}{ Attitude } & Between Groups & 184.122 & 2 & 92.061 & \multirow{3}{*}{16.393} & \multirow{3}{*}{$\begin{array}{l}0.000 \\
S\end{array}$} \\
\hline & Within Groups & 2791.078 & 497 & 5.616 & & \\
\hline & Total & 2975.200 & 499 & & & \\
\hline
\end{tabular}

Table (6): Association of the women knowledge and attitude regarding to oral contraceptive pills and number of children

\begin{tabular}{|c|c|c|c|c|c|c|}
\hline \multicolumn{2}{|l|}{ Categories } & \multirow{2}{*}{$\begin{array}{c}\begin{array}{c}\text { Sum of } \\
\text { Squares }\end{array} \\
136.970 \\
\end{array}$} & \multirow{2}{*}{$\frac{\text { df }}{2}$} & \multirow{2}{*}{$\begin{array}{c}\text { Mean Square } \\
68.485 \\
\end{array}$} & \multirow{4}{*}{$\frac{\text { F. }}{5.639}$} & \multirow{4}{*}{$\begin{array}{c}\text { Sig. } \\
\begin{array}{c}0.004 \\
\text { S }\end{array}\end{array}$} \\
\hline \multirow{3}{*}{\begin{tabular}{|l} 
General \\
Information
\end{tabular}} & Between Groups & & & & & \\
\hline & Within Groups & 6036.172 & 497 & 12.145 & & \\
\hline & Total & 6173.142 & 499 & & & \\
\hline \multirow{3}{*}{ Complication } & Between Groups & 4.115 & 2 & 2.058 & \multirow{3}{*}{0.911} & \multirow{3}{*}{$\begin{array}{c}0.403 \\
\text { N.S }\end{array}$} \\
\hline & Within Groups & 1122.893 & 497 & 2.259 & & \\
\hline & Total & 1127.008 & 499 & & & \\
\hline \multirow{3}{*}{ Benefits } & Between Groups & 12.595 & 2 & 6.297 & \multirow{3}{*}{1.775} & \multirow{3}{*}{$\begin{array}{c}0.171 \\
\text { N.S }\end{array}$} \\
\hline & Within Groups & 1763.205 & 497 & 3.548 & & \\
\hline & Total & 1775.800 & 499 & & & \\
\hline \multirow{3}{*}{ Attitude } & Between Groups & 15.367 & 2 & 7.683 & \multirow{3}{*}{1.290} & \multirow{3}{*}{$\begin{array}{c}0.276 \\
\text { N.S }\end{array}$} \\
\hline & Within Groups & 2959.833 & 497 & 5.955 & & \\
\hline & Total & 2975.200 & 499 & & & \\
\hline
\end{tabular}

\section{DISCUSSION}

Table (1) demonstrates the sociodemographic characteristics for the whole study sample. The table shows that the highest percentage of age group $(36 \%)$ and $(37 \%)$ was between (30-34) years and (35) years and above respectively. With regard to occupation of women, the table shows that the highest percentage $(78.2 \%)$ of them were housewife. As for the occupation of husband, the majority of the subjects (57.4\%) were free work. According to the level of education of women in the whole study, the primary school formed the highest percentage $(37.6 \%)$. With relation to level of education of husband in the whole study, the highest percentage ranged between primary school level (21.4\%) and institute (20.8\%). Regarding to the number of children, the majority of the subject (41\%), (40.4\%) had between (1-3) and (4-6) child. While only $(18.6 \%)$ of the women had seven and above child. With regard to socio-economic status, the table shows that the highest percentage $(59.2 \%)$ of them were barely sufficient socio-economic status. Finally, for the type of family in the whole study, nuclear family formed the highest percentage $(80.6 \%)$ while the extended family formed $(19.4 \%)$ only. The present study showed 
that more than one third of the current study samples were older in age 30 years and above, had a primary school education level with majority three quarters of them being house wife. According to the number of children, two fifth of the sample had children from (1-3) and (4-6) child, with majority of them being nuclear family and half of the sample living in a moderate socioeconomic status.

Table (2) shows the distribution of the study sample according to the reproductive history . According to the years of marriage, it was found that $(44.8 \%)$ of the women were married for 15 years and above, while $(5.8 \%)$ of them had less than 5 years of marriage, with a mean and SD (10-14 years) \pm 0.924 . Regardingto age of menarche, the table shows that $(62.4 \%)$ of the women started their menarche at (12-13 years), while only (1.6\%) of them started their menarche at age (16 andabove ), with a mean and SD (12-13years) $\pm 0.646 .(60.8 \%)$ of the women had a period of menstrual cycle from (46 days) and $(0.4 \%)$ of them had (10days and above).According to the regularity of the menstrual cycle, the table shows that $(67.6 \%)$ of the women had a regular menstrual cycle, while $(32.49 \%)$ had irregular menstrual cycle. On the other hand, (56\%) of the subject had moderate pain during menstruation and $(35.4 \%)$ had severe pain, while only (8.6\%) of them had mild pain during menstruation. In regard to the quantity of menstruation, (66.2\%) of the women had a normal amount of menstruation, while (9.4 $\%)$ had heavy menstruation. According to gravidity, the result shows that $(53 \%)$ of the sample had (4-6) pregnancies, and (33.2\%) had from (1-3) pregnancies. While only (13.8\%) of the sample had seven and above pregnancies, with a mean and SD (1-3) \pm 0.658 . The (63\%) of the women had null miscarriage and abortion and only (2.2\%) had seven and above miscarriage and abortion. Regarding parity, the highest percentage $(51.4 \%)$ of the study sample had (4-6 deliveries), while the lowest percentage (9.2\%) of them had (seven and above deliveries). (39.2.\%) of the study sample started using the contraceptive pills from (1-3) years and (34.2\%) of them started from (4-6) years .On the other hands (50.8.\%) and (49\%) of the women get the contraceptive pills from the family planning center and primary care and pharmacy. Regarding to the type of family planning used previously, (44.2\%) of the women were using pills and $(28.4 \%)$ used combined condom and pills, while $(7.4 \%)$ and $(0.2 \%)$ used injection and condom respectively. Table (3) shows that the highest grand mean score is (2.86) for" mother's attitude regarding to oral contraceptive pill" and the lowest grand mean score (2.78) for" the general information about oral contraceptive pills". The result shows that the grand mean score for all mothers awareness and attitudes regarding to oral contraceptive pills are (2.83) $\sim 2.8$. While, the table (4) shows that there is a highly significant association between women knowledge and attitudes regarding to oral contraceptive pills and their level of education at $P$. value $\leq 0.05$. Table (5) shows that there is a significant association between women knowledge and attitude regarding to oral contraceptive pills and their occupation at $\mathrm{P}$. Value $\leq 0.05$. This table shows that there is no significant association between women knowledge and attitudes regarding to oral contraceptive pills and number of children, at $P$. value $\leq 0.05$, except for the "General information regarding to oral contraceptive pills" category is significant. The figure (1) shows that the highest percentage $(59.6 \%)$ of the study sample had null chronic disease, $(0.6 \%)$ had heart disease and (22.6\%) had others which include; (arthritis (joint pain), hemorrhoids, irritable bowel syndrome, obstetric problems). Although some studies (Khan, 1976; Kumar et. $a l ., 2005)$ stated that women do not practice family planning methods even though they had a good knowledge, for example the study by Sharma and Sharma (1991), which showed that $(60.8 \%)$ had knowledge regarding family planning methods, while only (19\%) were using the contraceptive irregularly, another reason for irregularity use was desire of both the women and the men to have more children. This result disagrees with my study findings as it showed a grand mean of score (2.78) for the women information which include general information, complication and benefits regarding to oral contraceptive pills. Shendge et. al. (2012) found a good knowledge of various methods of contraception for example, (99.7\%) for sterilization of the women, $(65 \%)$ for the men. About oral contraceptive pills (94.6\%), while only $(94 \%)$ was found for natural and other methods. Women in this study mostly preferred oral contraceptive $(39.7 \%)$ followed by female sterilization (29\%) for the condom users (15.7\%). Another cross sectional study of hundred women to determine the frequency of knowledge, attitude and practice regarding contraception of parous women revealed that majority of the sample were educated housewives $(78 \%)$, while (55\%) of them were from lower middle class 
(Shendge et. al., 2011). Majority of the women (70\%) received information from a health professional. Male condom was used by (57\%), (43\%) used injection and $(33 \%)$ used oral contraceptive pills. Mahadeen and Hamdan (2012) found that women who had used family planning were asked what method they had ever used, showed that oral contraceptive pills and the IUD were the most used methods $31.1 \%$ and $24.6 \%$ respectively, $19.4 \%$ had ever used withdrawal method, while only $10.1 \%$ of them used injection.

My study investigated the type of family planning used previously found that $44.2 \%$ were using oral contraceptive, condom and pills were $28.4 \%$, IUD were $19.8 \%$, injection $7.4 \%$ and condom $0.2 \%$ respectively. It is clear from this that my study sample prefers using contraceptive pills rather than other methods and this may due to pills using is more simple and easy than other methods. There are many factors that affect using contraceptives for family planning, such as religion, type of family, socioeconomic status and fear from the side effects of using contraceptives, as well as educational level which is considered to exert most profound effect on family planning acceptance and fertility. In other words, education is the most dynamic and influential tool for inducing positive attitude among couples towards the methods and measures of family planning (Dingra et. al., 2010). Knowledge regarding family planning associated with educational level, it increases with the increasing of educational level. Arbab (2011) reported that knowledge regarding family planning increase with the increasing of educational level, women with secondary education or those with college/ university education were more likely to know about family planning compared with women with lower educational levels. Furthermore, younger women under 25 years were more likely to have lack of knowledge of family planning. In addition, fewer women with lower monthly household income knew about contraceptives than those with higher income. These results disagree with my study as the majority of my sample had a primary school level education, however, their knowledge was adequate for the whole categories. This can be explained as the educational sessions that were being conducted in the typical primary health care centers by the family planning center's staff as successful programs. A significant association was found for the women knowledge and attitudes regarding to oral contraceptive pills and educational level at $(\mathrm{p}<0.0005)$. Regarding to socioeconomic status, my results disagree with the above study, as my sample were living in moderate socioeconomic status, however there was no significant association for women knowledge and attitudes regarding to contraceptive pills and socioeconomic status at $(p<0.325)$ and $(p<0.364)$ respectively. In addition, non-significant association was found for the women knowledge and attitudes regarding to contraceptive pills and their age at a level (p. value < 0.0636) and (p. value <0.851) respectively.

Knowledge regarding family planning associated with occupation of women, it adequate knowledge, in my study the sample mostly being a housewife. The findings of this study agree with a study by (Hazim, 2000) on the nursing process in family planning, the result of the study reported that the majority of the women were housewives and constituted (95.00). The same result was found in (Samira et. al., 2011) of being the study sample housewife. In addition, non-significant association was found for the women knowledge and attitudes regarding to contraceptive pills and their occupation at level $(\mathrm{p}<0.974)$ and $(\mathrm{p}<0.947)$ respectively. According to the number of children, in my study of being mostly of the women were have (1-3) children and above, a study by (Kyla, 2011) on the knowledge, attitudes and practices regarding family planning in southern Rajasthan agree with my study. The data analysis revealed that there is a significant between women knowledge regarding to oral contraceptive oils and number of children, except for the "mothers attitude regarding to oral contraceptive pills "category. Regarding parity, the highest percentage of the study sample had (4-6 deliveries), my result agree with the study by (on the knowledge, attitude and practices of contraception among married women, and my result disagree with the study by (Sanaa et. al., 2014) on Certain Determinants Affecting the Current choice of family planning methods used by women Attending some family planning clinics in Baghdad city; In this study most of the women in the sample had (3-4 deliveries) and the minority of them had (1-2 deliveries). In addition, a non-significant association was found for the women knowledge and attitudes regarding to contraceptive pills and their parity at level ( $\mathrm{p}$. value $<0.440)$ and (p. value $<0.076$ ) respectively.

\section{CONCLUSION}

The knowledge and attitudes of the women regarding to contraceptive pills were high. A 
significant relationship between (level of education, number of children) and knowledge regarding to contraceptive pills were found. In addition, A significant relationship between level of education and attitude regarding to contraceptive pills were found.

\section{RECOMMENDATIONS}

Increase the community awareness regarding the use of family planning methods especially the oral contraceptive pills through; the mass media and providing them with scientific booklets, pamphlets and journals, Necessity of involving all primary health care centers in urban and rural areas regarding family planning programs, Activate the role of family planning centers at General Hospitals in Kirkuk city , Further studies to include sample from rural areas and compare their awareness with the urban women regarding family planning methods, in particular contraceptive pills, Health education at the first postnatal visit for the women should be done after a live birth to wait at least two years, but not more than five years before trying to become pregnant again and for miscarriage or induced abortion, women should wait at least six months before trying to become pregnant again. In addition, further research should focus on using larger samples in order to gain a more accurate picture of family planning in the general population.

\section{REFERENCES}

Arbab, A.A.; Bener, A. and Abdulmalik, M. (2011). Prevalence ,awareness and determinants of contraceptive use in Qatari women. Eastern Mediterranean Health Journal ,La Revue de Santé de Ia Mediterranean orientale. 17 (1).

Berkeley. (2009). University of California. Oral contraceptives (pill). Online Appointment www.uhs.berkeley.edu.150.

Bhabanipegu, BhanupratapsinghGaur.; Nalinisharma, Ahanthemsantasingh. (2014). Knowledge ,attitude and practices of contraception among married women. International Journal of Reproduction, contraception, obstetrics and gynecology. 3(2). P.p.385-388.

Conde -Agudelo A.; and Belizan, JM. (2000). Maternal Morbidity and Mortality associated with inter pregnancy interval: cross sectional study. $B \quad M \quad J . \quad 321$. P.p.1255-1259.

Dingra, R.; Manhas, S.; Kohli, N. (2010). Attitude of Couples towards Family planning. Journal of Human Ecology. 30(1). P.p.63-7.

Hazim, Salwa G. (August, 2000).Nursing Process in Family Planning Centre. University of Mosul, college of nursing. MSc. Dissertation.

Jaypee-Annamma, Jacob, A. (2008). Comprehensive Text-Book of Midwifery. ( $2^{\text {nd }}$ ed.).

Khan, W A. (1976). Astudy of knowledge, attitude ,and practice of family planning in West pakistan. pak J. Fam plan. 1. P.p.1-10.

Kumar, S.; Priyadarshni, A.; Kant, S.; Anand, K.; Yadav, BK. (2005). Attitude of women towards family planning methods and its use Study from a slum of Delhi. Kathmandu University Medical Journal. 3(11). P.p.259-262.

Kyla, Donnelly. (July, 2011). Accredited Health Activists' Knowledge, Attitudes and Practices Regarding Family Planning in Southern Rajasthan. DRAFT. 2.

Mahadeen, A.I.; and Hamdan, A.M. (2012). Knowledge ,attitudes and practices to wards family planning among women in the rural southern region of Jordan. EsternMediterrean Health Journal.

Motant, T. (2008). Advance in oral contraceptive pills. The Canadian Journal of diagnosis.

Multiple indicator cluster survey. (2006). Reproductive health, Implementing agencies :central organization for statistics and information technology. Kurdistan regional statistics office.vol.1.

Murray -Mckinney. (2010). Foundation of maternal - newborn and women's health nursing. (5 ${ }^{\text {th }}$ ed.).

Phsouk, V.; Siriku, I.; Sutham, N.; and Nipunporn,V. (2003). Compliance of pregnant women regarding Iron supplementation in Vientiane Municipality, Lao P.D.R. Journal of public health and Development. 11(1).P.p.41-52.

Rajni, Dhingra; Sarika, Manhas; Nidhi, Kohli; and Asiya, Mushtaq. (2010). Attitude of Couples towards Family planning. $J$ HUM Ecol. 30 (1).P.p.63-70.

Samira, M. Ebrahim; Nihad K. Muhamed. (2011). Knowledge, Attitude and practices of family planning among women in Basrah city south of Iraq. the medical Journal of Basrah University.

Sanaa, Jafar Hamodi AKaisi; Amjad, Daoud Niazi. (2014). Certain Dertminants 
Affecting the current choice of Family Planning methods used by women Attending some Family Planning clinics in Baghdad city. Middle east Journal of family medicine. 12(7).

Shafei, MN.; Shah, MS.; Tengku, Ismail TA. (2012). Knowledge and Attitude towards Family planning practice and prevalence of Short Birth Spacing Among Residents of Suburban Area in Terengganu ,Malaysia, J. Community Me Health Educ2. 180.doi: 10711.1000180,

Sharma, V.; Sharma, A.(1991). Family Planning Practices among tribal of Rajasthan, India. $J$ Res Edu Indian Med. 10(4). P.p.5-9.

Shendge, HB.; Padhi, M.; Mishra, K. 2012). Dynamics of contraceptive use in women attending a tertiary care hospital. I JRRMS. 1.2(4).

Sonia, Naqvi; Nazia, Hashim; Nabila, Zareen; and Hassan, Fatima. (2011). Knowledge, attitude and practice of parous women Regarding contraception. Journal of the college of physicians and surgeons Pakistan. 21(2). P.p.103-105.

Stefano,Gennarini, J.D. (2013). Reducing population reduces tax revenues ,prosperity population control efforts among the poor in America. ESTwww.life sitenews.com.

Susan, H.(2006). Use of oral contraceptives in women with migraine ,Family medicine, women's medical group of Irvine, Irvine ,CA.

Timothy, C.; Okech, Nelson, W.; Tom, K. (2011). Contraceptive Use among women of Reproductive Age in Kenya's.

Usha, R.; Lynnette, M.; Tersia, Salvador V.; Armando, G.; Juan, R.; and Renaldo, M. (2004). Multiple Micronutrient supplements during Pregnancy do not reduce Anemia or Improve Iron status compared to Iron only supplements in semirural Mexico. the Journal of nutrition. (134). P.p.898-908. 